Tạp chi Khoa học và Công nghệ, Số 28, 2017

\title{
ADAPTIVE WAVELET FUZZY CMAC TRACKING CONTROL FOR INDUCTION SERVOMOTOR DRIVE SYSTEM
}

\author{
NGO THANH QUYEN, NGO DINH NGHIA, PHAM CONG DUY \\ Industrial University of Ho Chi Minh City; \\ ngothanhquyen@iuh.edu.vn,ngodinhnghia@iuh.edu.vn,phamcongduy@iuh.edu.vn
}

\begin{abstract}
In this study, a control system is proposed for the induction servomotor to achieve the highprecision speed tracking based on wavelet fuzzy cerebellar model articulation controller. In this proposed scheme, the wavelet fuzzy cerebellar model articulation controller (WFCMAC) is used to imitate an ideal controller due to it incorporates the advantages of the wavelet decomposition property with a fuzzy CMAC fast learning ability and the smooth compensator controller with bound estimation is designed to attenuate the effect of the approximation error caused by the WFCMAC approximator. The online tuning laws of WFCMAC and the smooth compensator with bound estimation parameters are derived in gradient-descent learning method and Lyapunov function so that the stability of the system can be guaranteed. Finally, through the experimental results of proposed control system is developed for induction servomotor is provided to verify the effectiveness of the proposed control methodology even the dynamical model of the induction servomotor is complete unknown.
\end{abstract}

Keywords. Wavelet, Cerebellar model articulation controller (CMAC), uncertain nonlinear systems, servomotor.

\section{INTRODUCTION}

In general, Field-oriented methods [1], [2] have been used in the design of induction motor drives for high-performance applications. With these control approaches, the dynamic behavior of the induction motor is similar to that of a separately excited dc motor. However, in the field-orientated method, the decoupled relationship is obtained by means of a proper selection of state coordinates, under the hypothesis that the rotor flux is kept constant. Therefore, the uncertainties of the plant, such as mechanical parameter uncertainty and external load disturbance in practical applications are difficult to obtain. To deal with these uncertainties, some intelligent techniques have been adopted to control the induction servomotor drive systems [3]-[5]. Liaw and Lin [3] proposed a model-following fuzzy adaptation mechanism to reduce the effects of parameter variations; however, the fuzzy rules must initially be constructed by a time-consuming trial-and-error tuning procedure. Chan and Wang [4] proposed a sliding-mode control for the rotor flux and torque using two independent control variables; however, their control algorithm is based on the plant model. Lin et al. [5] developed a rotor timeconstant estimator based on the model reference adaptive system and designed a robust speed controller by using fuzzy NN uncertainty observer; however, this design procedure is overly complex.

Recently, many applications have been implemented quite successfully based on wavelet neural networks (WNNs) which combine the learning ability of network and capability of wavelet decomposition property [6-9]. Different from conventional NNs, the membership functions of WNN is wavelet functions which are spatially localized, so, the WNNs are capable of learning more efficiently than conventional NNs for control and system identification as has been demonstrated in $[6,8]$. As a result, WNNs has been considerable interest in the applications to deal with uncertainties and nonlinearity control system as is shown in [8-9].

To deal with disadvantages of NNs, cerebellar model articulation controller (CMAC) was proposed by Albus in 1975 [10] for the identification and control of complex dynamical systems, due to its advantage of fast learning property, good generalization capability and ease of implementation by hardware [11-13].

In this paper, a fuzzy CMAC (FCMAC) is proposed, which incorporates the fuzzy inference system with a CMAC. The wavelet analysis procedure is implemented with dilation and translation parameters of a mother wavelet [14] - [18]. Then, by combining a wavelet with an FCMAC, a novel wavelet FCMAC 
(WFCMAC) is also proposed in this paper. This WFCMAC combines the advantages of FCMAC fast learning ability and wavelet decomposition capability for control applications. In the proposed control scheme, a WFCMAC is utilized to mimic an ideal controller, and the parameters of the WFCMAC are online tuned by the derived adaptive laws. Moreover, a smooth compensator with bound estimation is design to efficiently suppress the influence of approximation error between the ideal controller and the WFCMAC so that the system stability can be achieved. Finally, experimental results are presented to illustrate the effectiveness of the proposed control scheme.

This paper is organized as follows: The indirect field oriented induction motor drive is described in section II. Section III presents adaptive WFCMAC control system. Experiment results of the induction servomotor are provided to demonstrate the speed tracking control performance of the proposed adaptive WFCMAC system in section IV. Finally, conclusions are drawn in section V.

\section{INTRODUCTION}

A block diagram of the indirect field-oriented induction motor drive system is shown in Fig. 1, which consists of an induction motor loaded with a DC machine, a ramp-comparison current-controlled pulse-width-modulated (PWM) voltage-source inverter, an indirect field-oriented mechanism, a coordinate translator, a unit vector $\left(\cos \left(\theta_{d}\right)+j \sin \left(\theta_{d}\right)\right.$, where $\theta_{d}$ is the position of rotor flux) generator, and a position controller [2], [19]. The induction servomotor used in this drive system is a three-phase Yconnected two-pole $400 \mathrm{~W} 60-\mathrm{Hz}$ type. For the position control system, the braking machine is driven by a current-source drive to provide braking torque. With the implementation of field-oriented control [1][3], the mechanical equation of an induction servomotor drive can be simplified as

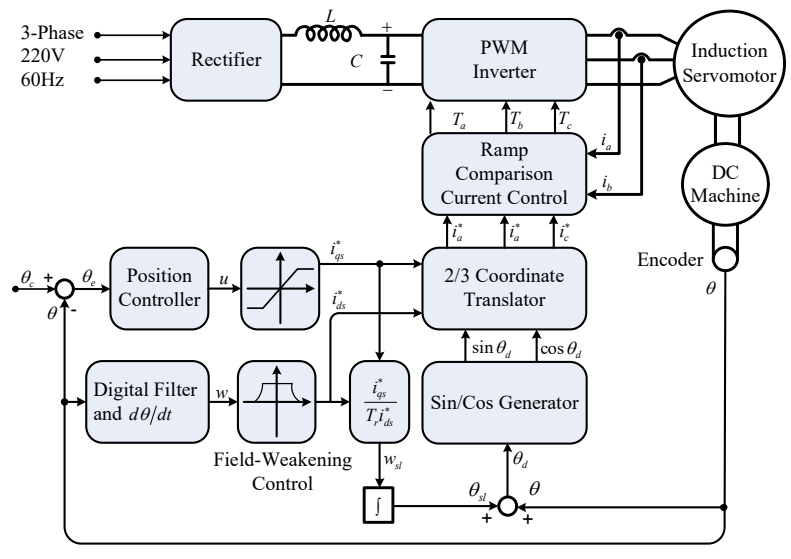

Fig. 1. System configuration of nonlinear decoupled induction motor servo drive.

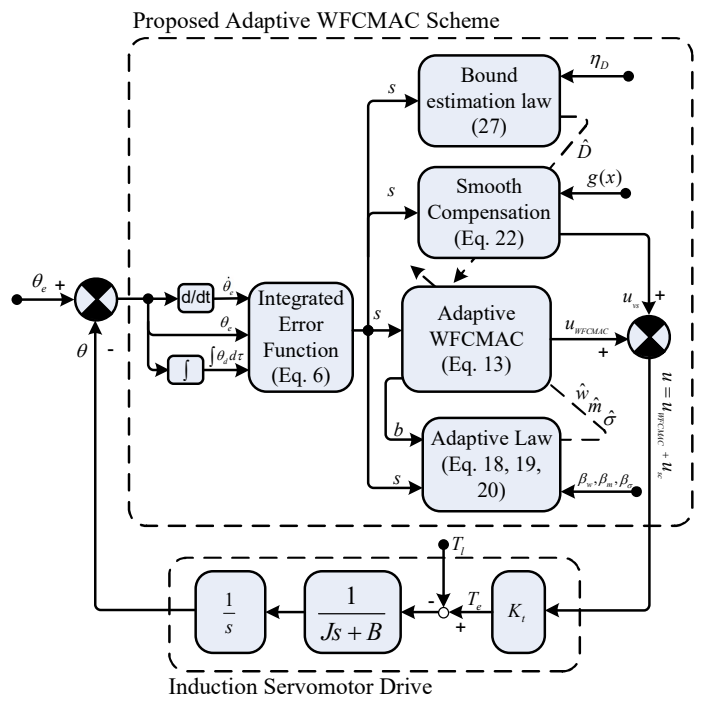

Fig. 2. System configuration of nonlinear decoupled induction motor servo drive.

$$
J \ddot{\theta}(t)+B \dot{\theta}(t)+T_{l}=T_{e}
$$

where $J$ is the moment of inertia, $B$ is the damping coefficient, $\theta$ is the position, $T_{l}$ represents the external load disturbance, and $T_{e}$ denotes the electric torque defined as:

$$
\begin{aligned}
& T_{e}=K_{t} i_{q s}^{*} \\
& K_{t}=\left(\frac{3 n_{p}}{2}\right)\left(\frac{L_{m}^{2}}{L_{r}}\right) i_{d s}^{*}
\end{aligned}
$$


Where $k_{t}$ is the torque constant, $i_{q s}^{*}$ is the torque current command, $i_{d s}^{*}$ is the flux current command, $n_{p}$ is the number of pole pairs, $L_{m}$ is the magnetizing inductance per phase, and $L_{r}$ is the rotor inductance per phase. Then, the induction servomotor drive system can be represented in the following form:

$$
\ddot{\theta}(t)=-\frac{B}{j} \dot{\theta}(t)+\frac{K_{t}}{j} i_{q s}^{*}-\frac{1}{j} T_{l} \sqsupset f(x)+g(x) u(t)+L(x)
$$

Where $f(x)=-B \dot{\theta}(t) / j, g(x)=K_{t} / j, u(t)=i_{q s}^{*}(t)$ is the control effort, and $L(x)=-K_{t} / j$ represents the external load disturbance and the unstructured uncertainty and due to nonideal field orientation in transient state and the unmodeled dynamics in practical application.

The control purpose is to design a control system such that the system output can track a desired trajectory signal $\theta_{c}(t)$. Define the tracking error as

$$
\theta_{e}(t)=\theta_{c}(t)-\theta(t)
$$

Suppose that an integrated error function is defined as

$$
s(t)=\dot{\theta}_{e}(t)+k_{1} \theta_{e}(t)+k_{2} \int_{0}^{t} \theta_{e}(\tau) d \tau .
$$

where $k_{1}$ and $k_{2}$ are nonzero positive constants. Assuming that the parameters of the system are well known and the external load disturbance is measurable, from (4), a feedback linearization control law can be obtained [15]

$$
u^{*}=\frac{1}{g(x)}\left[\ddot{\theta}_{c}-f(x)-L(x)+k_{1} \dot{\theta}_{e}+k_{2} \theta_{e}\right]
$$

Substituting (7) into (4) gives

$$
\ddot{\theta}_{e}+k_{1} \dot{\theta}_{e}+k_{2} \theta_{e}=0
$$

If $k_{1}$ and $k_{2}$ are chosen to correspond to the coefficients of a Hurwitz polynomial, that is, a polynomial whose roots lie strictly in the open left half of the complex plane. However, the ideal controller in (7) can not determine, because of $L(x)$ is exactly unknown for practical applications. So, in order to this problem, a proposed adaptive WFCMAC control system is shown in Fig. 2 which comprises a WFCMAC $u_{W F C M A C}$ and a smooth compensator $u_{S C}$ as follows:

$$
u=u_{W F C M A C}+u_{s c}
$$

Where $u_{W F C M A C}$ is the main controller used to approximate the ideal control in (7) and $u_{S C}$ the smooth compensator is utilized to compensate for the approximation error between the ideal controller and $u_{W F C M A C}$.

\section{ADAPTIVE WFCMAC CONTROL SYSTEM}

\subsection{Brief of the WFCMAC}

The main difference between the FCMAC and the original CMAC is that association layer in the FCMAC is the rule layer which is represented as follows. 


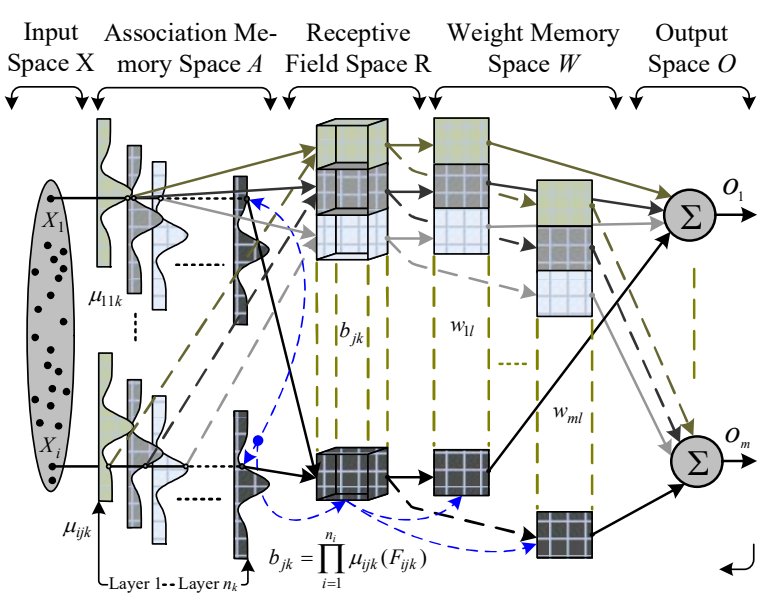

Fig. 3. Architecture of a WFCMAC

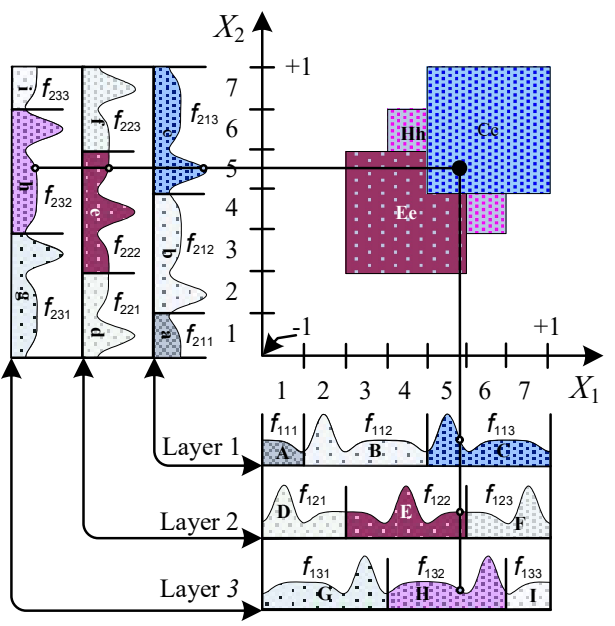

Fig. 4. Block division of WFCMAC with wavelet function

$R^{l}:$ if $X_{1}$ is $\mu_{1 j k}$ and $X_{2}$ is $\mu_{2 j k}, \cdots, X_{n_{i}}$ is $\mu_{i j k}$ then $O_{j k}=w_{j k}$ For $i=1,2, \cdots, n_{i}, j=1,2, \cdots, n_{j}$,

$k=1,2, \cdots, n_{k}$ and $l=1,2, \cdots, n_{k} n_{j}$.

Where $n_{i}$ is the number of the input dimension, $n_{j}$ is the number of the layers for each input dimension, $n_{k}$ is the number of blocks for each layer, $l=n_{k} n_{j}$ is the number of the fuzzy rules and $\mu_{i j k}$ is the fuzzy set for ith input, jth layer and kth block, $w_{j k}$ is the output weight in the consequent part.

A novel WFCMAC is represented and shown in Fig. 3. It is combines a wavelet function with the FCMAC including input, association memory, receptive field, and output spaces. The signal propagation is introduced according to functional mapping as follows:

1. The first mapping $X: X \rightarrow A$ : assume that each input state variable $X=\left[\begin{array}{llll}X_{1} & X_{2} & \cdots & X_{n_{i}}\end{array}\right]$ can be quantized into $n_{e}$ discrete states and that the information of a quantized state is regarded as region a wavelet receptive-field basic function for each layer. The mother wavelet is a family of wavelets. The first derivative of basic Gaussian function for each layer is given here as a mother wavelet which can be represented as follows:

$$
\mu_{i j k}\left(F_{i j k}\right)=-F_{i j k} \exp \left[-\frac{F_{i j k}^{2}}{2}\right], i=1,2, \cdots, n_{i}, \quad k=1,2, \cdots, n_{k}
$$

Where $F_{i j k}=\left(X_{i}-m_{i j k}\right) / \sigma_{i j k}, m_{i j k}$ is a translation parameter and $\sigma_{i j k}$ is dilation.

2. The second mapping $A: A \rightarrow R$ : the information $\mu_{i j k}$ of each $k$ th block and each $j$ th layer relates to each location of receptive field space. The Fig. 4 illustrates a structure of two-dimension $\left(n_{i}=2\right)$ WFCMAC with wavelet basic function with $n_{j}=3$ and $n_{k}=3$ case. Areas of receptive field space is formed by multiple-input regions are called hypercube; i.e. in the fuzzy rules in (10), the product is used as the "and" computation in the consequent part. The firing of each state in $j$ th each layer and $k$ th each block can be obtained the weigh of each hypercube corresponding. assume that in 2-D WFCMAC case is shown in Fig. 4, where input state vector is $(6,3)$, then, the content of $l$ th hypercube can be obtained as follows:

$$
b_{j k}=\prod_{i=1}^{n_{i}} \mu_{i j k}\left(F_{i j k}\right) \quad \text { For } j=1,2, \cdots, n_{j} \text { and } k=1,2, \cdots, n_{k}
$$

3. Finally, The WFCMAC output is the algebraic sum of the activated weighs with the hybercube elements. The output mathematic form can be expressed as follows: 


$$
u_{W F C M A C}=o=w^{T} b=\sum_{j=1}^{n_{j}} \sum_{k=1}^{n_{k}} w_{j k} b_{j k} \quad \text { For } j=1,2, \cdots, n_{j}, k=1,2, \cdots, n_{k} \text { and } i=1,2, \cdots, n_{i} .
$$

\subsection{Adaptive WFCMAC control system}

In (7), the uncertainty is always unknown, so cannot be implemented. A WFCMAC approximator will be used to estimate the uncertainty. By the universal approximation theorem, there exists a WFCMAC to approximate [20].

$$
u^{*}=u_{W F C M A C}\left(s, w_{j k}, m_{i j k}, \sigma_{i j k}\right)+\varepsilon
$$

Where $\varepsilon$ denotes the approximation error. By taking the time derivative of (6) and using (4), (5) and (9). We have

$$
\dot{s}=\ddot{\theta}_{e}+k_{1} \dot{\theta}_{e}+k_{2} \theta_{e}=-f(x)-g(\underline{x})\left(u_{W F C M A C}+u_{s c}\right)+\ddot{\theta}_{c}-L(x)+k_{1} \dot{\theta}_{e}+k_{2} \theta_{e}
$$

The energy function is defined as

$$
V(s(t))=\frac{1}{2} s^{2}(t)
$$

By multiplying both sides of (15) by $s$, yields

$$
\dot{s} s=-s f(x)-s g(\underline{x})\left(u_{W F C M A C}+u_{s c}\right)+s\left(\ddot{\theta}_{c}-L(x)+k_{1} \dot{\theta}_{e}+k_{2} \theta_{e}\right)
$$

With the energy function $V(s(t))$, the parameters updating law based on the normalized gradient descent method can be derived as follows

The updating law for the $k t h$ weight memory can be derived according to

$$
\dot{\hat{w}}_{j k}=-\beta_{w} \frac{\partial s \dot{s}}{\partial u_{W F C M A C}} \frac{\partial u_{W F C M A C}}{\partial \hat{w}_{j k}}=\beta_{w} s g(x) \hat{b}_{j k}\left(F_{i j k}\right)
$$

Where $\beta_{w}$ is positive learning rate for the output weight memory $w_{j k}$.

The translations and dilations of the $k$ th mother wavelet function can be also updated according to

$$
\begin{aligned}
& \dot{\hat{m}}_{i j k}=-\beta_{m} \frac{\partial s \dot{s}}{\partial u_{W F C M A C}} \frac{\partial u_{W F C M A C}}{\partial \hat{b}_{j k}} \frac{\partial b_{j k}}{\partial f_{i j k}} \frac{\partial f_{i j k}}{\partial \dot{\hat{m}}_{i j k}}=-\beta_{m} s g(x) \hat{w}_{j k} b_{j k} \frac{1-F_{i j k}^{2}}{\left(X_{i}-\hat{m}_{i j k}\right)} \\
& \dot{\hat{\sigma}}_{i j k}=-\beta_{\sigma} \frac{\partial s \dot{s}}{\partial u_{W F C M A C}} \frac{\partial u_{W F F M A C}}{\partial \hat{b}_{j k}} \frac{\partial b_{j k}}{\partial f_{i j k}} \frac{\partial f_{i j k}}{\partial \hat{\sigma}_{i j k}}=-\beta_{\sigma} s g(x) \hat{w}_{j k} b_{j k} \frac{1-F_{i j k}^{2}}{\hat{\sigma}_{i j k}}
\end{aligned}
$$

Where $\beta_{m}$ and $\beta_{\sigma}$ are positive learning rates for the translation $\hat{m}_{i j k}$ and dilation $\hat{\sigma}_{i j k}$.

\subsection{Smooth compensator controller with bound estimation}

The most useful property of WFCMAC is its ability to approximate linear or nonlinear mapping through learning. In (14), the approximation error is assumed to be bounded by where is a positive constant and denotes one norm. The error bound is assumed to be a constant during the observation; however, it is difficult to measure it in practical applications. Therefore, a bound estimation is developed to estimate this error bound. Define the estimation error of the bound.

$$
\tilde{D}=D-\hat{D}
$$

Where $\hat{D}$ is the estimated value of $D$. The smooth compensator controller is designed to compensate for the effect of the approximation error and is chosen as

Substituting (9) into (4) yields

$$
u_{s c}=-g(s) \hat{D} \operatorname{sgn}(s)
$$

$$
\ddot{\theta}(t)=f(x)+g(x)\left(u_{W F C M A C}+u_{s c}\right)+L(x)
$$

After some straightforward manipulations, the error equation governing the system can be obtained through (7), (9), (14), and (4) as follows:

$$
\dot{s}=\ddot{\theta}_{e}+k_{1} \dot{\theta}_{e}+k_{2} \theta_{e}=g(x) u_{s c}+\varepsilon
$$


The following Lyapunov function candidate is chosen as:

$$
L=(s, \tilde{D})=\frac{1}{2} s^{2}+\frac{\tilde{D}^{2}}{2 \eta_{D}}
$$

Where $\eta_{D}$ is a positive constant. Differentiating (25) with respect to time and using (14), (21), (24) and (15), it can be obtained that

$$
\dot{L}=(s, \tilde{D})=s^{T} \dot{s}+\frac{\tilde{D} \tilde{\tilde{D}}}{\eta_{D}}=s^{T}(\varepsilon-\hat{D} \operatorname{sgn}(s))+\frac{\tilde{D} \dot{\tilde{D}}}{\eta_{D}}=\left(s^{T} \varepsilon-\hat{D}\|s\|_{1}\right)+\frac{\tilde{D} \dot{\tilde{D}}}{\eta_{D}}
$$

If the estimation law is chosen as

$$
\dot{\tilde{D}}=-\dot{\hat{D}}=-\eta_{D}\|s\|_{1}
$$

then (26) can be rewritten as

$$
\dot{I}=(s, \tilde{D})=s^{T} \varepsilon-\hat{D}\|s\|_{1}-(D-\hat{D})\|s\|_{1}=\left(s^{T} \varepsilon-D\|s\|_{1}\right) \leq\left(\|s\|_{1}\|\varepsilon\|_{1}-D\|s\|_{1}\right)=-\left(D-\|\varepsilon\|_{1}\right)\|s\|_{1} \leq 0
$$

Since $\dot{I}<0$ that is $\dot{L}(s(t), \tilde{D}(t)) \leq \dot{L}(s(0), \tilde{D}(0))$, it can be inferred that $s(t)$ and $\tilde{D}$ are bounded. Let function $\Xi=\left(D-\|\varepsilon\|_{1}\right) s \leq\left(D-\|\varepsilon\|_{1}\right)\|s\|_{1} \leq-\dot{I}(s, \tilde{D})$, and integrate function $\Xi$ with respect to time

$$
\int_{0}^{t} \Xi(\tau) d \tau=L(s(0), \widetilde{D})-L(s(t), \widetilde{D})
$$

Because $L(s(0), \widetilde{D})$ is bounded, and $L(s(t), \widetilde{D})$ is nonincreasing and bounded, the following result is obtained:

$$
\lim _{t \rightarrow \infty} \int_{0}^{t} \Xi(\tau) d \tau<\infty
$$

In addition, since $\Xi(t)$ is bounded, by Barbalat's Lemma, it can be shown that $\lim _{t \rightarrow \infty} \Xi(t)=0$. That is, $s(t) \rightarrow 0$ as $t \rightarrow \infty$. As a result, the AWFCMAC system is asymptotically stable. Moreover, the tracking error of the control system, $\theta_{e}(t)$, will converge to zero according to $s(t) \rightarrow 0$. In summary, the AWFCMAC system is presented in (9), where the parameters $\hat{w}, \hat{m}$ and $\hat{\sigma}$ of the WFCMAC controller are adjusted by (18), (19) and (20), respectively, and the smooth compensator controller $u_{s c}$ is given in (22) with bound estimation law of smooth compensator controller is updated by (27). By applying these adaptive control laws, the AWFCMAC control system can be guaranteed to be stable in the Lyapunov sense.

\section{EXPERIMENTAL RESULTS}

In this section, the proposed control system is applied for the Induction servomotor speed tracking control. Moreover, for illustrating the superior of the proposed control scheme, the experiments of the proposed controller, the proportional-integral (PI) controller and the CMAC controller are given for comparison. The parameters of the nominal model of the drive system are given as: $K_{t}=0.573 \mathrm{~N} . \mathrm{m} / \mathrm{A}$, $J=4.93 \times 10^{-3} \mathrm{~N} . \mathrm{m} . \mathrm{s}^{2}, B=6.24 \times 10^{-3} \mathrm{~N} . \mathrm{m} . \mathrm{s} / \mathrm{rad}$. The proposed WFCMAC is characterized as in Fig. 3: $n_{i}=1, n_{e}=5, \rho=4, n_{j}=4, n_{k}=2, n_{l}=n_{j} n_{k}=4 \times 1=4, k_{1}=2, k_{2}=1, \beta_{w}=\beta_{m}=\beta_{\sigma}=\eta_{D}=0.01$. 


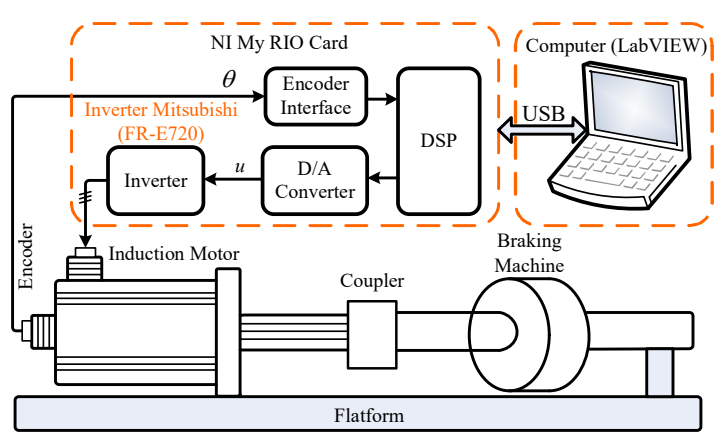

Fig. 5. Control system for field-oriented induction servomotor drive.

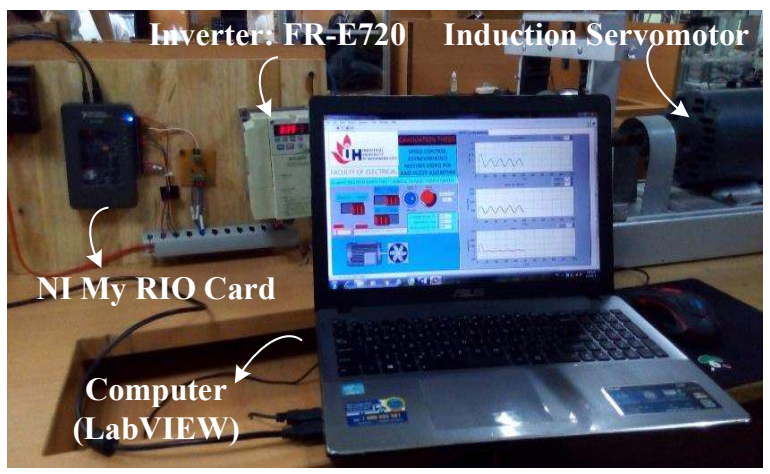

Fig. 6. Image of the experimental equipment..

Some experimental results are provided to further demonstrate the effectiveness of the proposed control design method. A block diagram and a image of the experimental equipment of the computer control system for the field-oriented induction servomotor drive is shown in Fig. 5 and Fig. 6. The control objective is to control motor speed to move periodically for a periodic step and to move periodically for a sinusoidal command. For comparison, a PI controller is implemented to control the induction servomotor first. The parameters of the PI controller are determined by trial and error to make the sinusoidal and periodic step command tracking responses close to the desired tracking performance. The parameters of the PI controller are chosen as $k_{p}=1.01, k_{I}=0.02$. The experimental results of the PI controller due to sinusoidal and periodic step commands are depicted in Fig. 7. The tracking response, tracking error and control effort, for the periodic step command are depicted in Fig. 7(a)-(c), and the tracking response, control effort, and tracking error for the sinusoidal command are depicted in Fig. 8(a)-(c), the adaptive CMAC control, The experimental results of the adaptive CMAC control system due to sinusoidal and periodic step commands are shown in Fig. 9, 10. The tracking response, control effort, and tracking error of the sinusoidal command are shown in Fig. 9(a)-(c), and the tracking response, control effort, and tracking error for the periodic step command are shown in Fig. 10(a)-(c). For the proposed adaptive WFCMAC control, The experimental results of the AWFCMAC control system due to sinusoidal and periodic step commands are shown in Fig. 11,12. The tracking response, control effort, and tracking error of the sinusoidal command are shown in Fig. 11(a)-(c), and the tracking response, control effort, and tracking error for the periodic step command are shown in Fig. 12(a)-(c).

The experimental results indicate that the high-accuracy (3.31 RPM and 18.5 RPM mean-square errors for sinusoidal and periodic step commands, respectively) trajectory tracking responses can be achieved by using the proposed AWFCMAC control system for different reference trajectories. This response is acceptable for the desired fast accurate servo system. Comparing to the PI and the adaptive CMAC controller, the tracking error has been much reduced, and the control chattering has been eliminated by using the proposed AWFCMAC. Moreover, the performance measure comparisons of the PI controller, adaptive CMAC controller and the proposed AWFCAMC for the tracking of sinusoidal and periodic step commands are shown in Table 1. This table indicates that, comparing the proposed AWFCMAC controller with the PI controller and the adptive CMAC controller, mean square errors have been reduced for the sinusoidal and periodic step commands, respectively. This indeed confirms the performance improvement of the proposed AWFCMAC control system. 

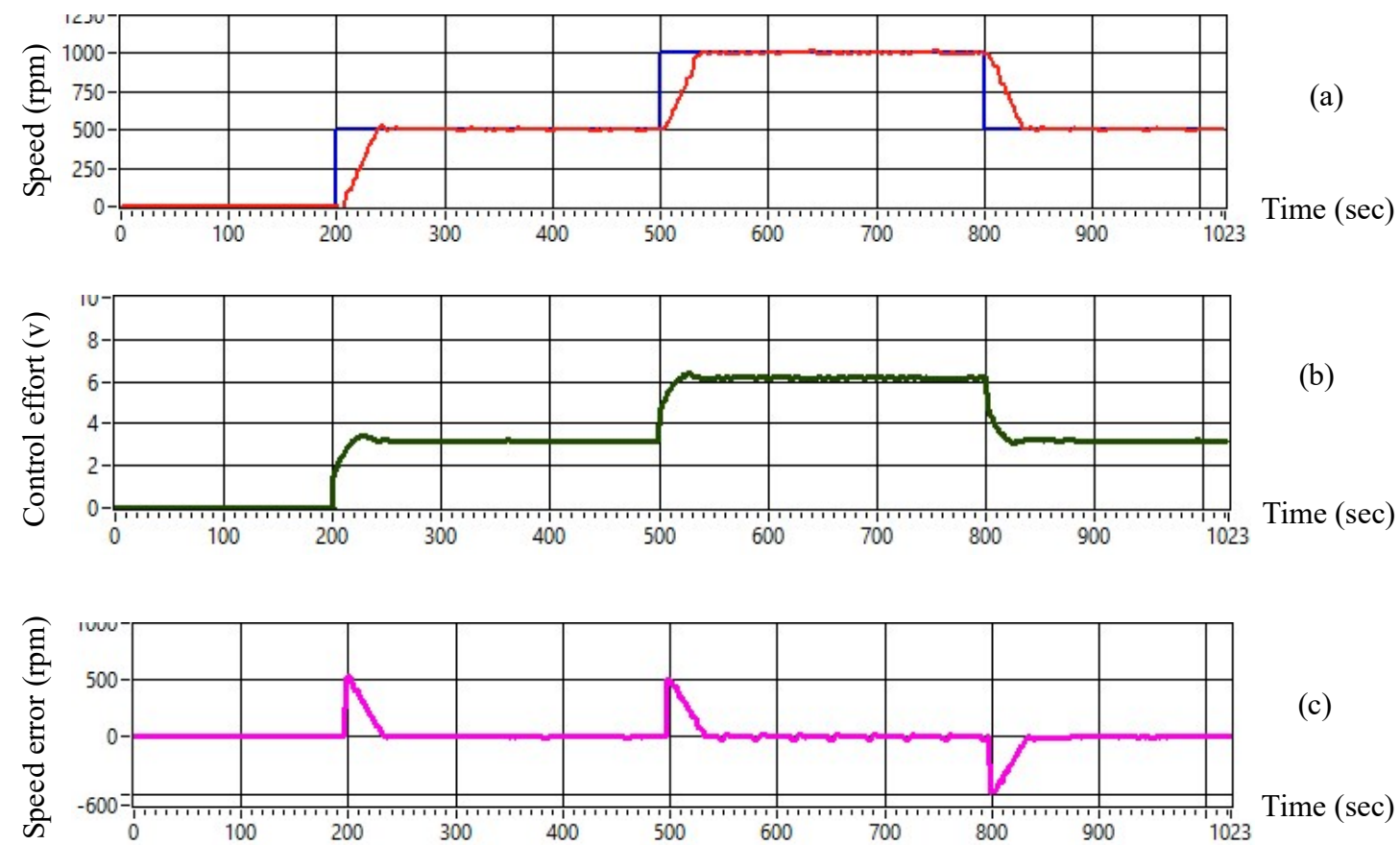

Fig. 7. Experimental results of PI system due to periodic step commands. (a) Tracking response. (b) Control effort. (c) Tracking error.
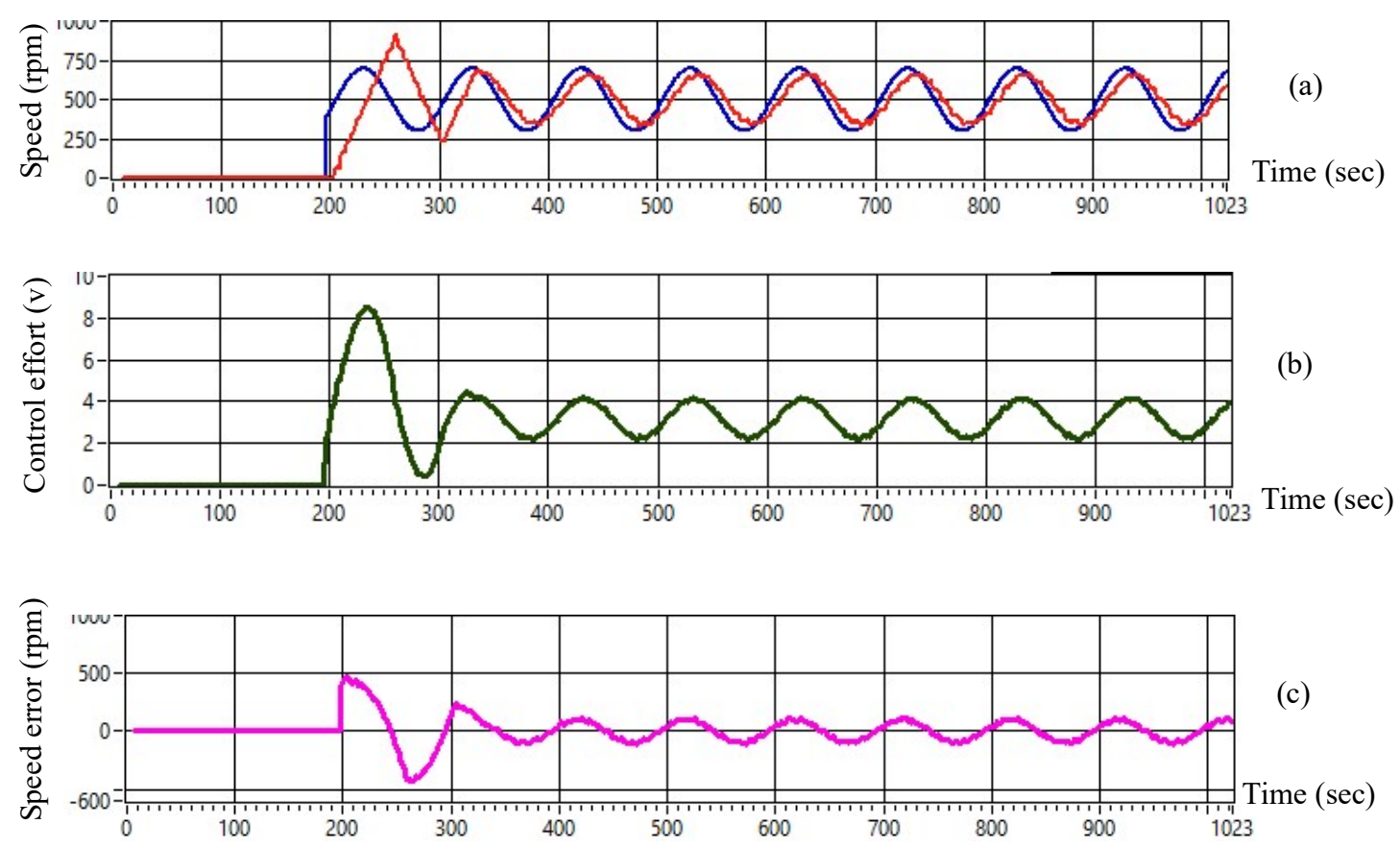

Fig. 8. Experimental results of PI system due to sinusoidal commands.

(a) Tracking response. (b) Control effort. (c) Tracking error. 

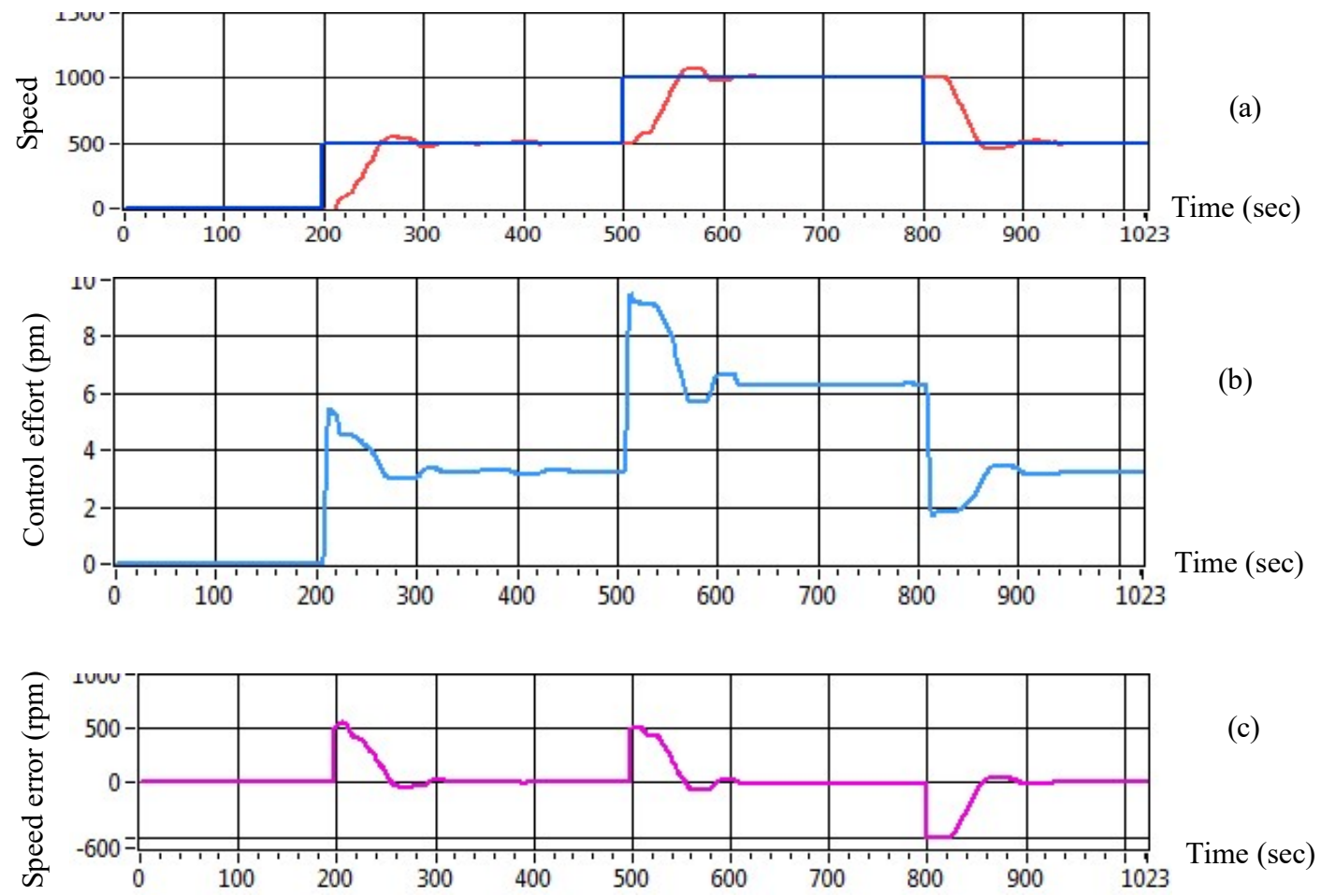

Fig. 9. Experimental results of adaptive CMAC system due to periodic step commands.

(a) Tracking response. (b) Control effort. (c) Tracking error.
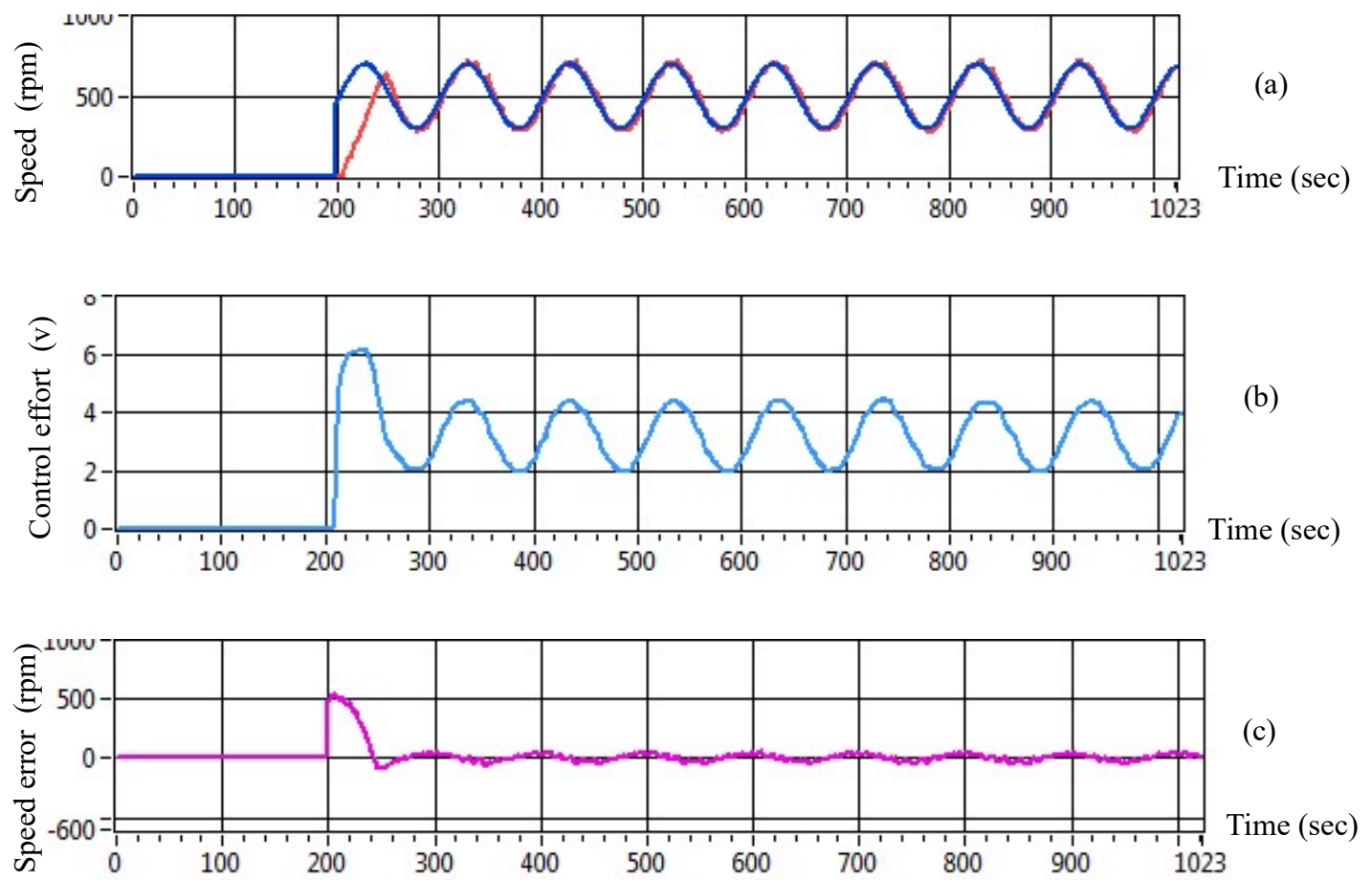

Fig. 10. Experimental results of adaptive CMAC system due to sinusoidal commands.

(a) Tracking response. (b) Control effort. (c) Tracking error. 

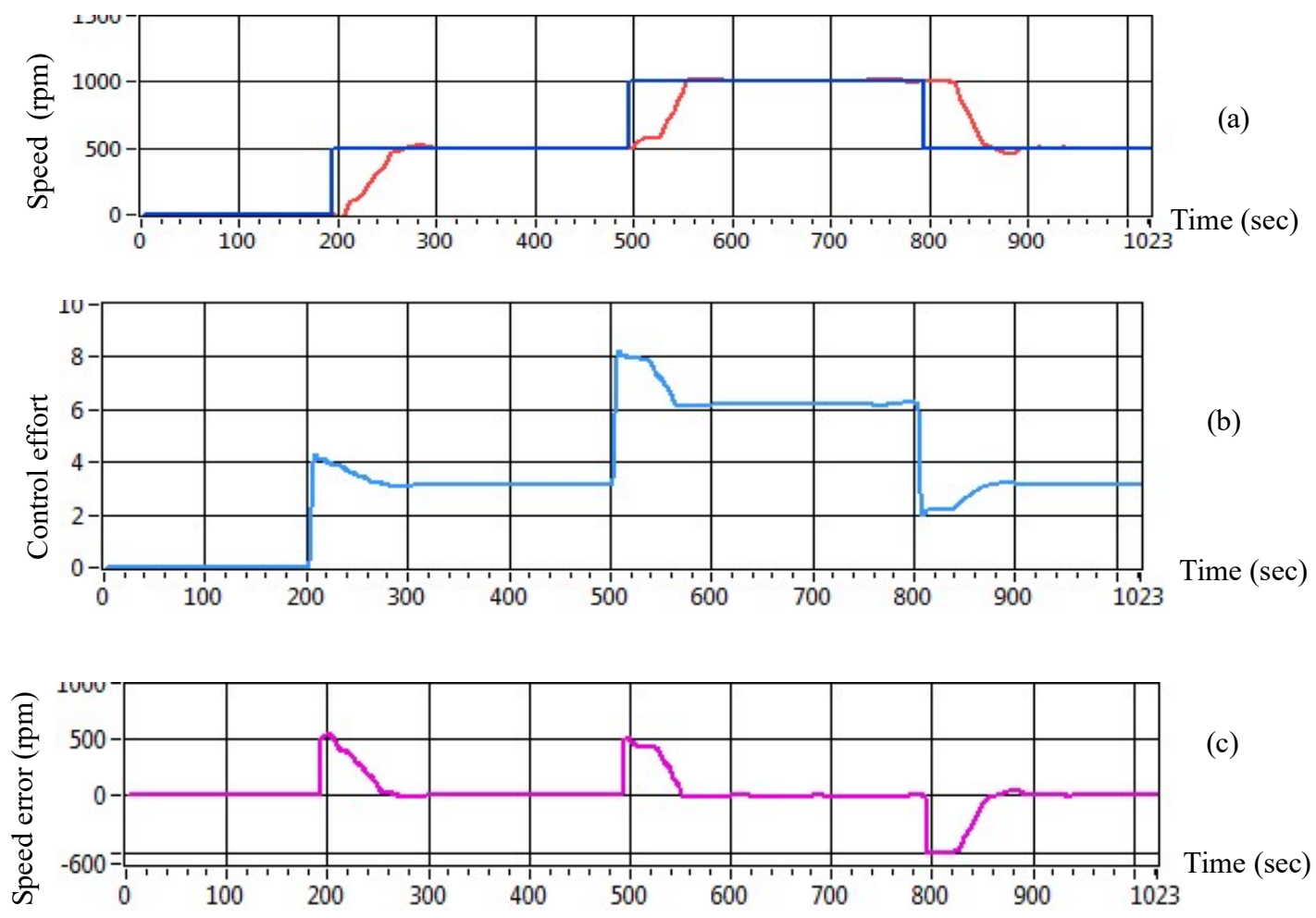

Fig. 11. Experimental results of proposed AWFCMAC system due to periodic step commands.

(a) Tracking response. (b) Control effort. (c) Tracking error.
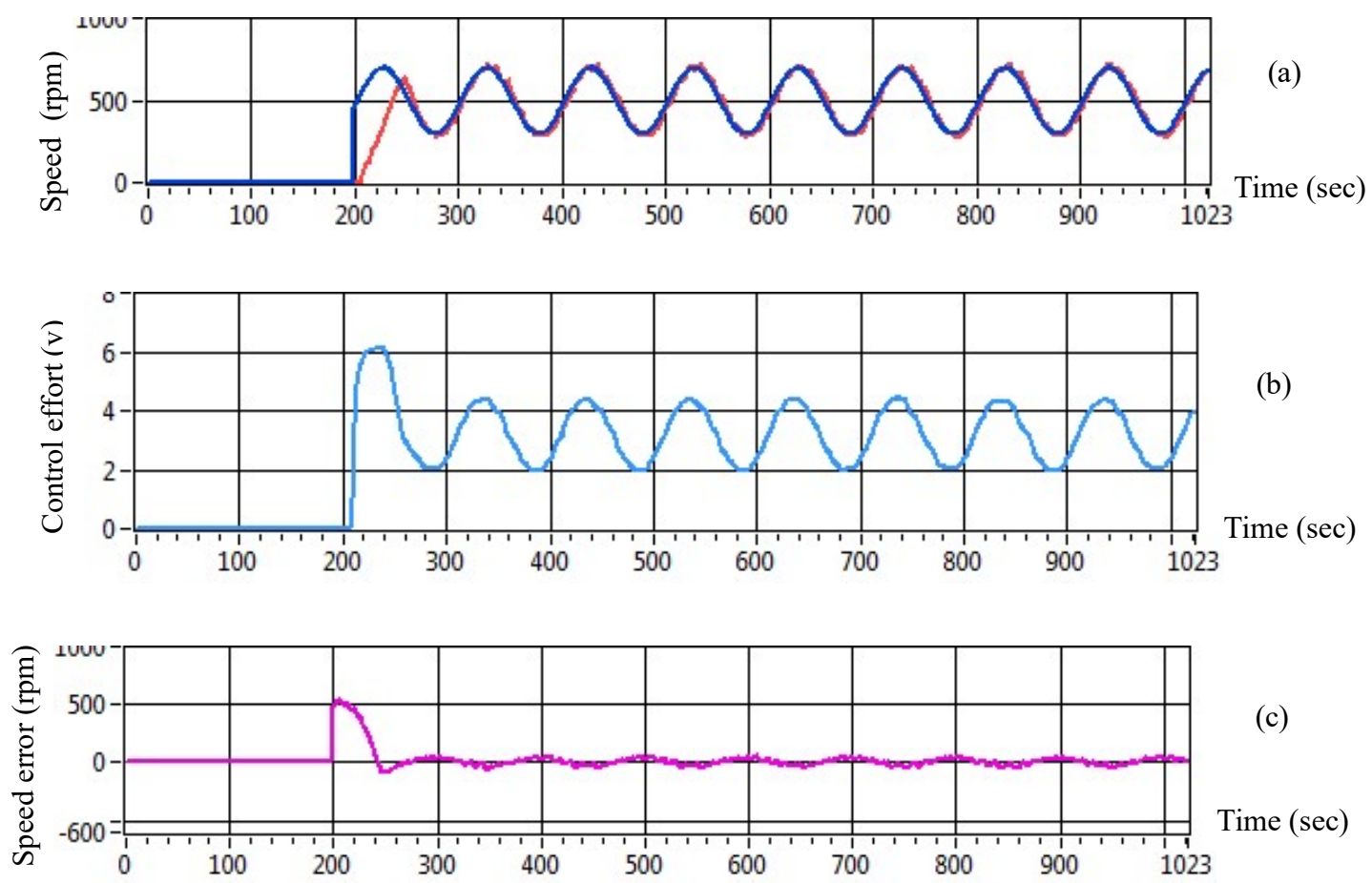

Fig. 12. Experimental results of CMAC system due to sinusoidal commands.

(a) Tracking response. (b) Control effort. (c) Tracking error. 
Table 1: Performance measures of the PI controller and AWFCMAC controller

\begin{tabular}{|c|c|c|c|}
\hline Sinusoidal command & PI Controller & ACMAC Controller & AWFCMAC Controller \\
\hline MSE & $5.6 \mathrm{RPM}$ & $4.12 \mathrm{RPM}$ & $3.31 \mathrm{RPM}$ \\
\hline Periodic step command & PI Controller & CMAC Controller & AWFCMAC Controller \\
\hline MSE & $55.7 \mathrm{RPM}$ & $19.8 \mathrm{RPM}$ & $18.5 \mathrm{RPM}$ \\
\hline
\end{tabular}

\section{CONCLUSION}

In this paper, an Adaptie WFCMAC system was proposed to control the rotor speed of an indirect field-oriented induction servomotor drive system. The proposed control system is composed of a WFCMAC and a smooth compensator with bound estimation. This WFCMAC is a generalization network of an FNN, a WNN, and a CMAC. The parameters of the proposed WFCMAC control system are tuned on-line and the system's stability has been proven in the Lyapunov sense. In addition, have demonstrated the effectiveness of the proposed control system. Thus, the proposed control system has the salient merits of model-free control design and favorable tracking performance. Aside from the Induction servomotor, the developed control technique can be applied to any servo control system.

\section{REFERENCES}

[1] B. K. Bose, Power Electronics and AC Drives. Englewood Cliffs, NJ: Prentice-Hall, 1986.

[2] D. W. Novotny and T. A. Lipo, Vector Control and Dynamics of AC Drives. New York: Oxford Univ. Press, 1996.

[3] C. M. Liaw and F. J. Lin, "Position control with fuzzy adaptation for induction servomotor drive," Proc. IEE-Elect. Power Applicat., vol. 142, pp. 397-404, 1995.

[4] C. C. Chan and H. Q. Wang, "New scheme of sliding-mode control for high performance induction motor drives," Proc. IEE—Elect. Power Applicat., vol. 143, pp. 177-185, 1996.

[5] F. J. Lin, R. J. Wai, C. H. Lin, and D. C. Liu, "Decoupled stator-fluxoriented induction motor drive with fuzzy neural network uncertainty observer," IEEE Trans. Ind. Electron., vol. 47, pp. 356-367, Apr. 2000.

[6] R. J. Wai, "Development of new training algorithms for neuro-wavelet systems on the robust control of induction servo motor drive," IEEE Trans. Ind. Electron., vol. 49, no. 6, pp. 1323-1341, Dec. 2002.

[7] F.F.M. EI-Sousy, "Robust wavelet-neural network sliding-mode control system for permanent magnet synchronous motor drives,” IET Electr. Power Appl., vol. 5, Iss. 1, pp. 113-132, 20011. 
[8] C. H. Lu, "Design and application of stable predictive controller using recurrent wavelet neural networks,” IEEE Trans. Ind. Electron., vol. 56, no. 9, pp. 3733-3742, Sep. 2009.

[9] F.-J. Lin, S.-Y. Chen, Y.-C. Hung "Field-programmable gate array-based recurrent wavelet neural network control system for linear ultrasonic motor," IET Electr. Power Appl., vol. 3, Iss. 4, pp. 289$312,2009$.

[10] J. S. Albus, "A new approach to manipulator control: The cerebellar model articulation controller (CMAC),"J. Dyn. Syst. Meas. Control, vol. 97, no. 3, pp. 220-227, 1975.

[11] H. Shiraishi, S. L. Ipri, and D. D. Cho, "CMAC neural network controller for fuel-injection systems,” IEEE Trans. Control Syst. Technol., vol. 3, no. 1, pp. 32-38, Mar. 1995.

[12] S. Jagannathan, S. Commuri, and F. L. Lewis, "Feedback linearization using CMAC neural networks," Automatica, vol. 34, no. 3, pp. 547-557, 1998.

[13] Y. H. Kim and F. L. Lewis, "Optimal design of CMAC neural-network controller for robot manipulators,” IEEE Trans. Syst. Man Cybern. C, Appl. Rev., vol. 30, no. 1, pp. 22-31, Feb. 2000.

[14] R. J. Wai, "Development of new training algorithms for neuro wavelet systems on the robust control of induction servo motor drive," IEEE Trans. Ind. Electron., vol. 49, no. 6, pp. 1323-1341, Dec. 2002.

[15] C. F. Hsu, C. M. Lin, and T. T. Lee, "Wavelet adaptive backstepping control for a class of nonlinear systems,” IEEE Trans. Neural Netw., vol. 17, no. 5, pp. 1175-1183, Sep. 2006.

[16] M. A. S. K. Khan and M. A. Rahman, "A novel neuro wavelet based selftuned wavelet controller for IPM motor drives,” IEEE Trans. Ind. Appl., vol. 46, no. 3, pp. 1194-1203, Jun. 2010.

[17] C. H. Lu, "Design and application of stable predictive controller using recurrent wavelet neural networks," IEEE Trans. Ind. Electron., vol. 56, no. 9, pp. 3733-3742, Sep. 2009.

[18] F. J. Lin, Y. C. Hung, and S. Y. Chen, "FPGA-based intelligent dynamic sliding-mode control using recurrent wavelet neural network for linear ultrasonic motor," IET Control Theory Appl., vol. 4, no. 9, pp. 1511-1532, Sep. 2010.

[19] R. J. Wai and F. J. Lin, "Fuzzy neural network sliding-mode position controller for induction servo motor drive,” Proc. IEE—Elect. Power Applicat., vol. 146, pp. 297-307, 1999.

[20] L. X. Wang, Adaptive Fuzzy Systems and Control: Design and Stability Analysis. Englewood Cliffs, NJ: Prentice-Hall, 1994. 


\section{ĐIỀU KHIỂN BÁM ĐUỔI WFCMAC THÍCH NGHI CHO HỆ THỐNG TRUYỀN ĐỘNG ĐỘNG CƠ SERVO CẢM ÚNG}

Tóm tắt. Trong nghiên cứu này, một hệ thống điều khiển được đề xuất cho động cơ servo cảm ứng để đạt được bám đuổi tốc độ chính xác cao dựa trên WFCMAC. Trong sơ đồ đề xuất, bộ điều khiển WFCMAC được sử dụng để bắt chước bộ điều khiển lý tưởng do nó kết hợp các ưu điểm của tính chất phân rã hàm wavelet với khả năng học nhanh của CMAC mờ và một bộ điều khiển bù trơn với ước lượng giới hạn được thiết kế để làm giảm sai số xấp xỉ gây ra bởi WFCMAC. Các luật điều chỉnh trực tuyến các tham số của WFCMAC và bộ bù trơn được tìm thấy dựa trên phương pháp giảm độ dốc và hàm Lyapunov để ổn định của hệ thống được đảm bảo. Cuối cùng, thông qua kết quả thực nghiệm của hệ thống điều khiển đề xuất được phát triễn cho động cơ servo cảm ứng được cung cấp để kiểm chứng hiệu quả của phương pháp đều khiển đề xuất thậm chí mô hình động lực học của hệ động cơ servo cảm ứng hoàn toàn không biết.

Keywords. Wavelet, CMAC, hệ thống phi tuyến không chắc chắn, Động cơ servo.

Ngày nhận bài: 22/07/2017

Ngày chấp nhận đăng: 21/11/2017 